\title{
Potential development scale of low- and non-carbon generation in the Far East of Russia under increasing decarbonization requirements
}

\author{
Tatiana Pankrushina ${ }^{*}$, and Andrey Khorshev ${ }^{1}$ \\ ${ }^{1}$ The Energy Research Institute of the Russian Academy of Sciences, Nagornaya str., 31-2, Moscow, Russian Federation
}

\begin{abstract}
The ratification of the Paris Agreement by Russia in 2019 will inevitably force the decarbonization of the Russian electric power industry in future. In this article the potential development scale of low- and non-carbon generation technologies in the Far East power system is considered using MESSAGE optimization model. The required conditions for effective development of new gas-fired as well as nuclear and RES power plants were analyzed, and the potential reduction of $\mathrm{CO}_{2}$ emissions was assessed. The results showed that the development of low- and non-carbon generation technologies in this region requires quite high carbon price or taxes.
\end{abstract}

\section{Introduction}

The increasing necessity to reduce the harmful effects on the environment in order to prevent anthropogenic climate change has led to international cooperation and development of such commitments like the Kyoto Protocol (2004) and the Paris Agreement (2016). Special attention is paid to reducing greenhouse gas (GHG) emissions, primarily carbon dioxide $\left(\mathrm{CO}_{2}\right)$. For more than a decade, many developed countries have focused on shifting their national economies and energy sectors to less carbon-intensive development path. Analysis of the experience of the leading countries of the world shows that the major achievements were obtained in the electric power industry. Significant structural changes of national power systems are accompanied by the formation of powerful technological segments of non-carbon (mainly based on renewable energy sources (RES), and on nuclear power plants (PP), in some countries) and low-carbon gas generation.

The commitments under the Paris Agreement and their further possible tightening will inevitably force the decarbonization of the Russian electric power industry. Particularly this also applies to the integrated power system (IPS) of the Far East of Russia, where the role of the most carbon-intensive coal generation is significant. As shown in Table 1, at present the share of thermal generation in the capacity and electricity generation mix of the IPS of the Far East is about $60 \%$. While the share of coal-fired power plants reaches $49 \%$ of the total installed capacity and $55 \%$ of electricity generation. Also, in September 2020 one more coal-fired power plant (Sovetskaya Gavan CHP) was commissioned, and in accordance with the electric power industry development scheme [1], another coal-fired power plant, Artemovskaya CHP-2, is planned to be put online in 2026. However, due to the planned decommissioning of outdated capacities, the total installed capacity of existing and planned coal-fired power plants is going to be reduced by $30 \%$ by 2030 , but they will continue to play significant role in the power system.

Table 1. Capacity (as of 01.01.2020) and electricity generation (as of 2019) mix of the IPS of the Far East

\begin{tabular}{|c|c|c|}
\hline & $\begin{array}{c}\text { Installed } \\
\text { capacity, } \mathrm{GW}\end{array}$ & $\begin{array}{c}\text { Electricity generation, } \\
10^{9} \mathrm{kWh}\end{array}$ \\
\hline Total: & 11,1 & 43,82 \\
\hline Hydro & 4,6 & 16,59 \\
\hline Thermal PP, incl. & 6,5 & 27,23 \\
\hline CHP, incl. & 3,7 & 16,15 \\
\hline gas & 7,3 & 2,4 \\
\hline coal & 3,0 & 13,7 \\
\hline Condensing, incl. & 2,7 & 11,08 \\
\hline gas & 0,3 & 0,6 \\
\hline coal & 2,4 & 10,5 \\
\hline
\end{tabular}

\section{The key assumptions}

In this paper we are assessing the potential development scale of low- and non-carbon technologies in the IPS of the Far East until 2050 under the tightening requirements for decarbonization while ensuring reliable and resilient power supply of consumers. In this paper following lowand non-carbon generation technologies are considered:

- nuclear power plants - both large $(\approx 1 \mathrm{GW})$ and small modular reactors (SMR);

- gas-fired power plants with advanced open and combined cycle gas turbines (CHP and condensing mode). The article also considers gas-fired distributed generation (DG) operating in close proximity to consumers. The approach to its representation in the optimization model was presented in [2];

_ utility-scale RES power plants such as large wind and solar PV power plants.

*Corresponding author: epos@eriras.ru 
The MESSAGE a capacity expansion optimization model by IAEA was used here to assess the potential development scale of low- and non-carbon generation technologies in the IPS of the Far East [3]. This tool has been widely and regularly used by the IAEA member states for studies of the sustainable development of their national energy systems.

The first stage of the study is devoted to the preparation of the key cost and performance characteristics for both existing and new generating technologies, as well as for grid facilities that are considered in the power system. The most laborious part of this stage is the preparation of cost and performance characteristics of new power plants. The analysis of Russian and foreign data allow us to make some assumptions of cost and performance characteristics for different types of generation technologies given in Tables 2 and 3. It should be noted that all the cost characteristics are given in rubles of 2019. The capital costs of various generating technologies presented in Tables 2 and 3 do not include so-called territorial climate coefficient, which is used to adjust capital costs to regional construction conditions This coefficient is specific for each region: for the Republic of Sakha (Yakutia) this coefficient is 1.99, for Primorye and Amur regions - 1.3, for the Khabarovsk region -1.195 .

In order to adequately present the features of the operation of the power system, special attention is paid to taking into account the seasonal, daily and hourly variation of both consumption and generation of electricity and heat. Usually, the tasks of intraday balancing of supply and demand are solved in short-term forecasts, but introduction of renewable energy sources, and the analysis of the possibilities of their large-scale development requires, at least, a preliminary assessment of their participation in the load schedules for mediumand long-term forecasts.

Although such a task can be effectively solved using special class of optimization or simulation models for dispatching capacity at hourly (or even smaller) intervals, but in this paper this assessment was carried out directly within the capacity expansion model.
In the paper following demand and supply variations were considered:

- seasonal variations of district heating demand;

- seasonal and intraday variation of electricity demand; - seasonal and intraday variation of RES-based generation, which is non-dispatchable and depends on weather conditions.

The main problem of modelling of such heterogeneous, time-varying processes is to determine necessary and sufficient number of time slices (intervals) within a year to adequately catch all of their features simultaneously. As an example, Fig. 1 and Fig. 2 show the annual and intraday variations of electricity and district heating demand (as a percentage of the peak load), as well as the potential generation of hydro, wind and solar PV power plants (as a percentage of their maximum output) for the Amur power system. It is clear that the electricity demand and RES electricity generation fluctuations practically do not correspond to each other, both in the annual and, especially, in the intraday profile.

The analysis of such curves for all regional power systems of the IPS of the Far East allowed us to determine the necessary number of annual and intraday time-slices for an adequate representation of the features of the heat and electricity demand as well as the RES and hydro generation. Therefore, in the optimization model we considered 8 seasons (months), 2 typical days (working days and weekend), each represented by 9 intraday intervals. It means that each year of the forecast period in the model is described using 144 time-slices.

For the purposes of this study, a model of the IPS of the Far East was developed, which includes 4 regional power systems and connections between them, more than 30 existing and under construction power plants, 12 new generation technologies (including distributed generation and RES power plants) and 3 types of new heat sources (including gas boilers at the consumer's site) for each of the regional power systems. The optimal capacity and generation mix is provided by minimizing of total discounted costs of meeting the forecasted demand for electricity, power and heat in the IPS of the Far East up to 2050 , taking into account the prolonged effect of investment decisions (10 years).

Table 2. Key cost and performance characteristics of thermal and nuclear power plants

\begin{tabular}{|c|c|c|c|c|c|c|c|c|c|c|}
\hline & Nuclear & SMR & $\begin{array}{c}\text { Coal- } \\
\text { SC }\end{array}$ & $\begin{array}{c}\text { Coal- } \\
\text { USC }\end{array}$ & $\begin{array}{c}\text { Coal } \\
\text { CHP }\end{array}$ & $\begin{array}{c}\text { Cond. } \\
\text { CCGT }\end{array}$ & $\begin{array}{c}\text { SC- } \\
\text { CHP }\end{array}$ & CC-CHP & $\begin{array}{c}\text { DG Gas } \\
\text { engine }\end{array}$ & DG SC \\
\hline $\begin{array}{c}\text { Overnight capital } \\
\text { cost, 10 } 0^{3} \text { RUB/kW }\end{array}$ & 106,0 & 300,0 & 66,1 & 77,7 & 76,0 & 36,0 & 39,7 & 47,7 & 81,4 & 74,0 \\
\hline Fixed O\&M, \% & 2,3 & 1,5 & 3,0 & 3,5 & 4,0 & 3,0 & 4,5 & 4,5 & 5 & 4,5 \\
\hline $\begin{array}{c}\text { Fuel cost, RUB } \\
\text { /kWh / Specific } \\
\text { fuel consumption, } \\
10^{-6} \text { tce/kWh }\end{array}$ & 0,22 & 0,22 & 298 & 266 & $364 / 212$ & 218 & $365 / 159$ & $243 / 152$ & $279 / 158$ & $461 / 178$ \\
\hline $\begin{array}{c}\text { Construction time, } \\
\text { year }\end{array}$ & 5 & 3 & 5 & 5 & 5 & 3 & 3 & 3 & 1 & 1 \\
\hline
\end{tabular}

\footnotetext{
${ }^{\text {a }}$ Model for Energy Supply Strategy Alternatives and their General Environmental Impact
} 
Table 3. Key cost and performance characteristics of RES power plants

\begin{tabular}{|c|c|c|}
\hline & Wind & Solar \\
\hline \multicolumn{3}{|c|}{ Overnight capital cost, $10^{3} \mathrm{RUB} / \mathrm{kW}$} \\
\hline 2020 year & 109,0 & 103,0 \\
\hline \multirow{2}{*}{2025 year } & 95,0 & 75,0 \\
\hline & 85,0 & 65,0 \\
\hline \multirow{2}{*}{2030 year } & 94,85 & 67,75 \\
\hline & 76,85 & 56,65 \\
\hline \multirow{2}{*}{2035 year } & 92,65 & 61,3 \\
\hline & 69,45 & 51,5 \\
\hline \multirow{2}{*}{2040 year } & 87,2 & 55,45 \\
\hline & 62,8 & 41,2 \\
\hline \multirow{2}{*}{2050 year } & 81,75 & 45,54 \\
\hline & 56,75 & 36,05 \\
\hline $\mathrm{O} \& \mathrm{M}, \%$ & 1,5 & 2,1 \\
\hline Construction time, year & 3 & 3 \\
\hline Capacity factor & \multicolumn{2}{|c|}{$\begin{array}{l}\text { Individual values in each } \\
\text { energy system, depending } \\
\text { on the wind potential and } \\
\text { insolation }\end{array}$} \\
\hline
\end{tabular}

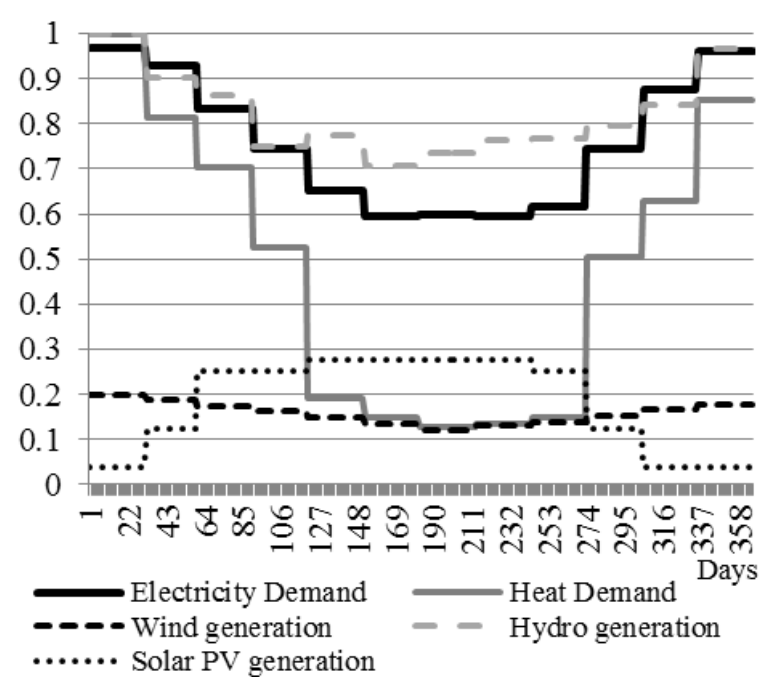

Fig. 1. Annual demand and RES generation curves of the Amur power system.

The forecast of electricity demand used in the model is based on the base scenario of the long-term forecast of socio-economic development of Russia, developed by the Ministry of Economic Development at the end of 2018. In the fall of 2019 the forecast was updated according to the parameters of the medium-term forecast and later adjusted for the crisis situation in 2020 - with the prolongation of the forecast trends in economic growth and electricity consumption indicators for the period up to 2050 (Table
4). According to this forecast, by 2050, the total electricity demand in the IPS of the Far East is going to increase by $40 \%$ compared to 2020 and will reach 61.8 billion $\mathrm{kWh}$ (including export from Amur to China). The district heating demand will be stable throughout the whole forecast period at the annual level of $22.610^{6} \mathrm{Gcal}$.

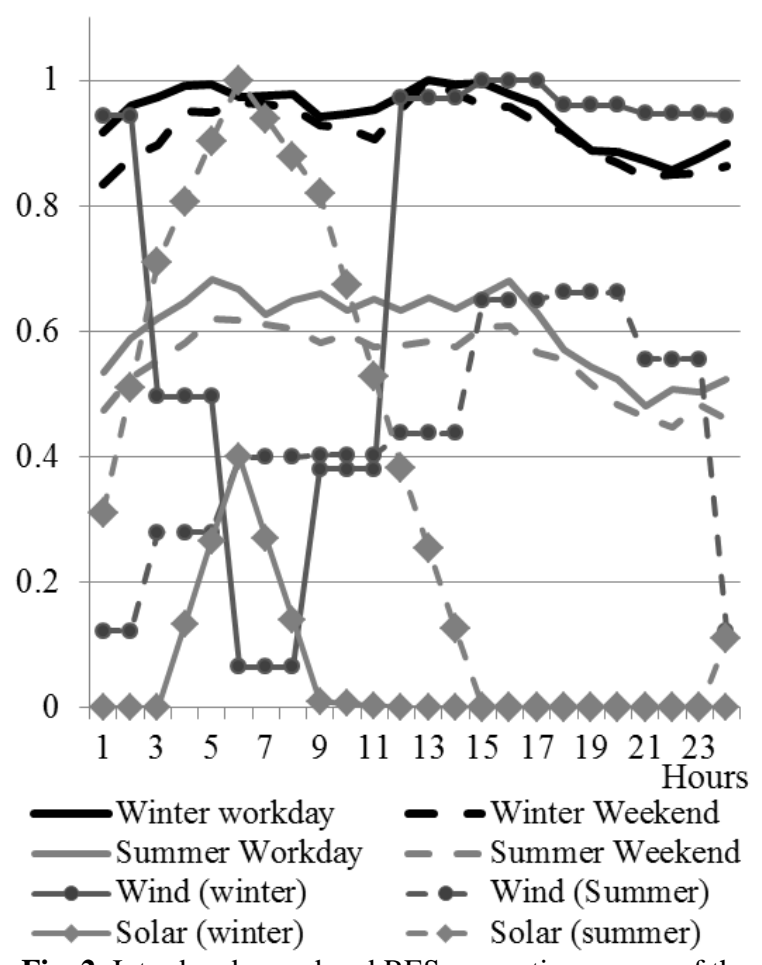

Fig. 2. Intraday demand and RES generation curves of the Amur power system (Moscow time)

\section{Considered scenarios}

First of all, reference Scenario A with a $7.5 \%$ discount rate, low fuel prices, and no $\mathrm{CO}_{2}$ emissions charges was considered to assess the optimal development scale of low- and non-carbon generating technologies in the IPS of the Far East in a "business as usual" setting.

However, assessments of the optimal capacity mix in the long-term forecasts are always characterized by high uncertainty in most of the initial data. That's why it becomes crucial to perform a multivariate analysis in order to determine the stability of the obtained results in conditions of varying the most significant factors in a given range.

The discount rate is one of the factors that can significantly increase the competitiveness of non-carbon capital-intensive technologies (primarily nuclear power plants). To assess the possibilities of expanding the potential development scale of nuclear power plants, we consider reducing the discount rate to $5 \%$ (scenario B).

Table 4. Forecast of electricity demand and the peak load in the IPS of the Far East up to 2050

\begin{tabular}{|c|c|c|c|c|c|c|c|}
\hline & 2020 & 2025 & 2030 & 2035 & 2040 & 2045 & 2050 \\
\hline Electricity demand (incl. export), $10^{9} \mathrm{kWh}$ & 43,9 & 48,8 & 54,2 & 58,2 & 59,4 & 60,6 & 61,8 \\
\hline Peak load, 10 $\mathrm{kW}$ & 6,5 & 8,0 & 8,8 & 9,4 & 9,5 & 9,7 & 9,8 \\
\hline $\begin{array}{c}\text { Capacity requirement incl. reserve margin } \\
\left(22 \% \text { of the peak load [4]), } 10^{6} \mathrm{~kW}\right.\end{array}$ & - & 9,8 & 10,8 & 11,5 & 11,6 & 11,8 & 12,0 \\
\hline
\end{tabular}


The gas and coal prices also have a significant impact on the future capacity mix. In the article gas and coal prices was considered in the range of values (Table 5). The upper price level corresponds to netback pricing model that will harmonize domestic and export gas prices by 2030 (scenario C), and the lower level assumes maintaining of the regulation of domestic gas market with price growth at a "not higher than inflation" rate.

The international experience shows that the introduction of $\mathrm{CO}_{2}$ prices or taxes is a fairly effective incentive to reduce $\mathrm{CO}_{2}$ emissions, but the scale of the reduction is determined by the level of this price or tax. It is still unlikely to expect the introduction of $\mathrm{CO}_{2}$ prices or taxes as a part of climate policy in Russia in the near and medium term due to the risks of a negative impact on macroeconomic indicators, inflation, as well as the competitiveness of Russian exports.

However, possible tightening of national commitments to reduce GHG emissions as well as the introduction of a climate component in international trade (i.e. carbon border adjustment proposed by the EU) may lead to the implementation and progressive increase of carbon prices, at least for the largest consumers of fossil fuels, including power plants, by 2030. To quantify the impact of this factor $\mathrm{CO}_{2}$ prices are considered in the range of values (Table 5) in our calculations. The lower level (Scenario D) assumes that $\mathrm{CO}_{2}$ prices will be introduced in 2030 at the level of $1300 \mathrm{RUB} / \mathrm{t} \mathrm{CO}_{2}$ and will remain stable up to 2050. While in Scenario E much higher $\mathrm{CO}_{2}$ prices are considered with their increase from $1300 \mathrm{RUB} / \mathrm{t} \mathrm{CO} \mathrm{CO}_{2}$ in 2030 to $6500 \mathrm{RUB} / \mathrm{t} \mathrm{CO}$ in 2050.

The last scenario $\mathrm{F}$ considered the most favorable conditions for the development of low- and non-carbon technologies, combining a low discount rate of 5\%, high prices of fossil fuels and high $\mathrm{CO}_{2}$ prices.

A brief description of all considered scenarios is presented in Table 6 . The optimal capacity and electricity generation mix obtained with all mentioned assumptions are presented in Fig. 3 and Fig. 4.

\section{Results}

The analysis of the results allowed us to make some general conclusions valid for all the scenarios:

- the capacity and electricity generation mix will change significantly by 2050 . Due to higher efficiency and lower capital costs, the share of gas-fired power plants (mainly condensing CCGTs) will increase significantly and substitute coal-fired power plants;

- the share of coal-fired thermal power plants will be sharply reduced - from $48.6 \%$ to about $3 \%$ in the capacity mix, as well as from $55 \%$ to $2 \%$ in the electricity generation mix, due to decommissioning of existing power plants;

- gas-based distributed generation is going to be developed - its share in the capacity mix will reach about $2.2-6.6 \%$, depending on the scenario, and in production mix $-3.4-8.0 \%$.

So, for the most scenarios the obtained capacity and electricity generation mix have a lot in common. Thus, in the reference scenario, low-carbon condensing CCGTs will play the main role in the power sector of the Far East. Their share will reach almost $50 \%$ in the capacity mix and about $57 \%$ in the generation mix in 2050 . The installed capacity of hydro power plants will remain stable, but their share will decrease to $35 \%$ in capacity mix and $28 \%$ in generation mix. These two types of generation technologies will provide $85 \%$ of total installed capacity and electricity generation. Looking from the one side it will significantly decrease the GHG emissions (for $35 \%$ in 2050 compared to 2020), but from the other side - such capacity and generation mixes are not very diversified. So reference scenario assumes that no non-carbon generation technologies are going to be introduces. These results are in line with LCOE calculations which showed that CCGTs are the cheapest option in such conditions [5].

Table 5. Forecast of electricity demand and the peak load in the IPS of the Far East up to 2050

\begin{tabular}{|c|c|c|c|c|c|c|}
\hline & 2025 & 2030 & 2035 & 2040 & 2045 & 2050 \\
\hline \multicolumn{7}{|c|}{ Natural gas prices, $10^{3}$ RUB/tce } \\
\hline \multirow{2}{*}{ Primorye region } & 4,06 & 3,94 & 3,92 & 3,98 & 3,98 & 3,98 \\
\cline { 2 - 7 } & 4,61 & 4,83 & 5,18 & 5,81 & 5,81 & 5,81 \\
\hline \multirow{2}{*}{ Amur and Khabarovsk regions } & 2,98 & 2,89 & 2,88 & 2,93 & 2,93 & 2,93 \\
\cline { 2 - 7 } & 4,14 & 4,36 & 4,71 & 5,33 & 5,33 & 5,33 \\
\hline \multirow{2}{*}{ Republic of Sakha (Yakutia) } & 3,64 & 3,54 & 3,52 & 3,58 & 3,58 & 3,58 \\
\cline { 2 - 7 } & 3,22 & 3,47 & 3,82 & 4,42 & 4,42 & 4,42 \\
\hline \multicolumn{7}{|c|}{ Coal prices, $10^{3}$ RUB/tce } \\
\hline \multirow{2}{*}{ Amur and Khabarovsk regions } & 2,91 & 2,83 & 2,82 & 2,86 & 2,86 & 2,86 \\
\cline { 2 - 7 } & 3,38 & 3,34 & 3,36 & 3,74 & 3,74 & 3,74 \\
\hline \multirow{2}{*}{ Republic of Sakha (Yakutia) } & 2,67 & 2,59 & 2,58 & 2,62 & 2,62 & 2,62 \\
\hline
\end{tabular}


Table 6. Key cost and performance characteristics of RES power plants

\begin{tabular}{|c|c|c|c|c|c|c|}
\hline Scenario & A & B & C & D & E & F \\
\hline $\begin{array}{c}\text { Discount } \\
\text { rate, \% }\end{array}$ & 7,5 & 5 & 7,5 & 7,5 & 7,5 & 5 \\
\hline $\begin{array}{c}\text { Fuel } \\
\text { price }\end{array}$ & $\min$ & $\min$ & $\max$ & $\min$ & $\min$ & $\max$ \\
\hline $\begin{array}{c}\mathrm{CO}_{2} \\
\text { price }\end{array}$ & - & - & - & $\min$ & $\max$ & $\max$ \\
\hline
\end{tabular}

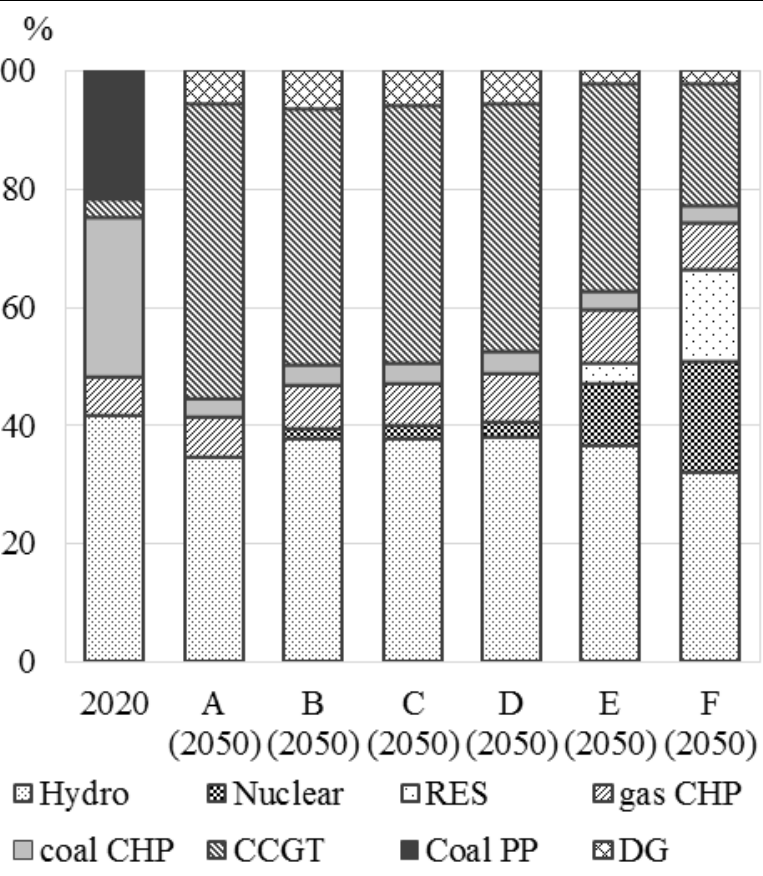

Fig. 3. The capacity mix of the IPS of the Far East, \%

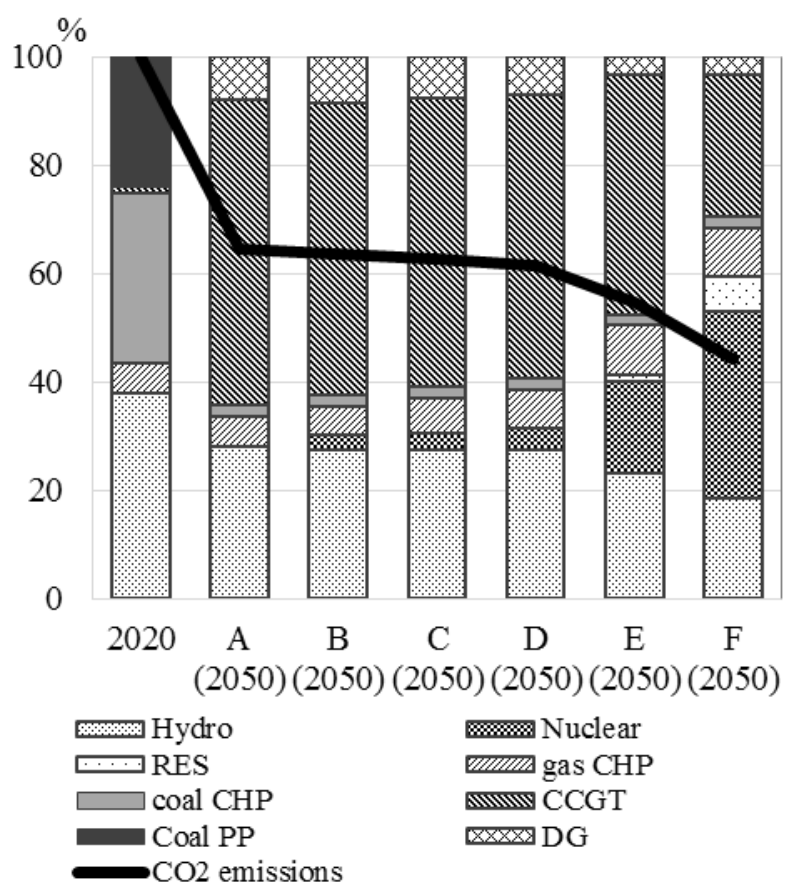

Fig. 4. The electricity generation mix of the IPS of the Far East and $\mathrm{CO}_{2}$ emissions reduction, $\%$

Consideration of a lower discount rate of $5 \%$ (scenario B) will increase the competitiveness of capital intensive nuclear power plants. That will provide the introduction of nuclear power plants both in generation and capacity mix, but at very low level. Their share will reach only $1.7 \%$ in the capacity mix and about $2.7 \%$ in the generation mix in 2050. It should be mentioned that the construction of a large nuclear power plant is possible only in Primorye region, where the reserved construction site is located. Also, such a low discount rate will increase the role of distributed generation to $6.6 \%$ in the capacity mix and $8.6 \%$ in the generation mix. These changes will be accompanied by a reduction of share of condensing CCGTs in both generation and capacity mix. In this scenario only $2 \%$ of $\mathrm{CO}_{2}$ emission reduction will be achieved compared to the reference scenario.

Consideration of higher fuel prices (scenario C) will provide results rather similar to scenario B, with only slight differences. The share of nuclear power plants will reach $2.1 \%$ in the capacity mix and $3.3 \%$ in the generation mix. The higher gas prices will cause more efficient application and increase share of gas cogeneration by decreasing share of condensing CCGTs and distributed generation. In this scenario the $\mathrm{CO}_{2}$ emissions will decrease only by $3 \%$ compared to the reference scenario (but by $63 \%$ compared to 2020).

Introduction of $\mathrm{CO}_{2}$ prices will further improve the results obtained in scenario $\mathrm{C}$. Introduction of rather low $\mathrm{CO}_{2}$ prices (scenario D) will even more increase share of nuclear power plants to $2.6 \%$ in the capacity mix and to $4.0 \%$ in the generation mix in $2050 . \mathrm{CO}_{2}$ emissions will be $5 \%$ lower than in the reference scenario.

In case of high $\mathrm{CO}_{2}$ prices (Scenario E) the installed capacity of nuclear power plants is going to increase significantly. With the introduction of $\mathrm{CO}_{2}$ price of 6500 rubles per ton of $\mathrm{CO}_{2}$ the capacity of a nuclear power plants in 2050 will reach 1,3 GW. This will account for about $10.3 \%$ of total installed capacity and about $16.8 \%$ of electricity production in the IPS of the Far East. These rather favorable conditions will also provide the development of non-carbon wind generation, but its share will be small in both capacity mix $(3.5 \%)$ and in the generation mix (1.4\%). Also, this scenario provides the largest decrease in the amount of $\mathrm{CO}_{2}$ emissions - about $15 \%$ compared to reference scenario and $45 \%$ compared to 2020 .

The most diversified capacity and generation mix is obtained under the most favorable conditions for decarbonization - a low discount rate, high fuel prices and high $\mathrm{CO}_{2}$ prices (scenario $\mathrm{F}$ ). In this scenario the largest share of non-carbon generation technologies will be achieved. More than a third of electricity will be produced by nuclear power plant, which share in the capacity mix will get to $18.7 \%$ (almost $2.7 \mathrm{GW}$ will be installed). Also, in this scenario both types of considered RES generation technologies will be developed. Their share in the capacity mix will reach $15.4 \%$, but only $6.4 \%$ in generation mix with almost $5 \%$ accounted for wind generation.

At the same time, the development of non-carbon technologies will lead to reduction of the share of condensing CCGTs in the capacity mix (down to 20.7\%) and in electricity generation mix (down to $26.2 \%$ ). This transformation of the structure of the electric power 
industry will lead to a reduction in GHG emissions by $30 \%$ compared to the reference scenario and about 55\% compared to 2020. So, share of non-carbon generation technologies (including hydro) will account for $66 \%$ in capacity mix and $59.3 \%$ in generation mix compared to $41.7 \%$ and $37.9 \%$ at present.

\section{Conclusion}

The results showed that the development of low- and noncarbon generation technologies in the IPS of the Far East is requiring strong carbon regulation. To achieve rather sizeable development of new non-carbon generation technologies it is necessary to introduce $\mathrm{CO}_{2}$ prices at a sufficiently high level. The main non-carbon generation technology in the IPS of the Far East will be nuclear power plants, which share in the electricity generation mix can be increased up to $18.7 \%$ by 2050 .

\section{Acknowledgment}

The research was supported by the Russian Science Foundation (project No. 17-79-20354).

\section{References}

1. The Ministry of Energy of the Russian Federation Act No. 508 of 30.06.2020 "The Scheme and Program for the Development of the Unified Energy System of Russia for 2020 - 2026 period“" (https://minenergo.gov.ru/en/node/19166)

2. T. Pankrushina, A. Khorshev. E3S Web of Conferences, vol. 114. Energy Systems Research, Methodical Approach to Assessing the Optimal Development Scale of Distributed Cogeneration in the UPS of Russia for the Long-Term (2019)

3. IAEA (Vienna), Nuclear Energy Series No. NG-T5.2 Modelling Nuclear Energy Systems with MESSAGE: A User's Guide, (2016)

4. The Ministry of Energy of the Russian Federation Act No. 281 of 30.06 .03 "Methodological recommendations for the energy systems development"

5. F. Veselov, I. Erokhina and T. Novikova, 2019 International Science and Technology Conference "EastConf", Long-Term Changes in Conditions for the Development of Conventional Thermal and NonCarbon Energy Technologies in the Power System of the Far East (2019) 